\title{
So what about history?
}

\author{
David A Bloom
}

The visibility of the past is an essential part of the present and a clue to the future. A physician is necessarily a historian, and it is the skill at listening to a patient and probing with relevant questions, to create a history, that makes the difference between mundane and extraordinary clinicians. These skills are honed by practice and experience.

History has further play in medicine, for each of us recognizes that by understanding the origin of the ideas, techniques, and tools that comprise our armamentarium we are able to deploy them cleverly and improve them. Skeptics might say that there is nothing new 'under the sun', but it is the reinvention and expansion of existing methodologies that is responsible for the ideas and technologies that largely fuel innovation.

Most importantly, the link between past and present perpetuates our culture and its intrinsic values. As physicians we cherish values that our predecessors explicated. The Hippocratic oath has survived 2.5 millennia because it contains values that continue to resonate with us. Survival of this oath is no less Darwinian than the conservation of DNA sequences and essential biological structures.

Another form of value transmission is in the stories of the past. Role models, ancient and new, inspire us. Galen, the Good Samaritan, Louis Pasteur, Florence Nightingale, William Osler, and Albert Schweitzer are easy examples, but countless others exist. One great gift of the human brain is the ability to study and celebrate the past, and every properly reconstructed story provides meaning.

Edward $\mathrm{O}$ Wilson, originator of the entire field of sociobiology, argues strongly for the
We use history

in our work

one patient at

a time, looking

for meaning in

their pasts. We

calibrate our

actions and

values with the

stories...from

the past.

DA Bloom is Professor of Urology and the Jack Lapides Professor of Urology in The Department of Urology, University of Michigan, Ann Arbor, MI, USA.

\section{Competing interests \\ The author declared he has no competing interests.}

www.nature.com/clinicalpractice doi:10.1038/ncpuro0200 idea of unity of knowledge, which he calls 'consilience'. Whereas human progress thus far has been distinguished by the branching of knowledge into defined fields, wherein a person can become an expert and create new knowledge, the crucial work for our future as a species will be at the interfaces among fields known or yet unknown.

So it is that our overarching culture is no less consequential than the fragments of new knowledge we produce. These fragments may be novel proteins that link DNA sequences and specific processes, new drugs, new vaccines, or systems to deliver healthcare. Yet our culture impels us to discuss priorities, to provide a decent safety net for the disadvantaged, to maintain integrity in our professions, and to inspire the next generation that will be our successors. The lessons of the past sustain our culture and maintain the visibility of our values.

So the question 'Why history?' is a rhetorical device. History is an absolute reality of today, it is what each moment and each advance is built upon. We use history in our work one patient at a time, looking for meaning in their pasts. We calibrate our actions and values with the stories and role models we bring from the past. We embed the significance of scientific pursuits in our culture and its values, which we can only truly know by looking back in time. As we increase the visibility of our past, telling and reinterpreting our stories, we sustain and grow our culture, providing context and clarity for our own day's work. So of course we use history in our medical work, but we can use it more to our advantage by practicing history deliberately in all its facets. 